\title{
Energy Management and Control Strategies of Electric Vehicle integrated into the Smart Grid
}

\author{
Kelly Kraatz \\ College of Sciences, Technology, and Engineering \\ James Cook University, Queensland, Australia \\ Kelly.kraatz@my.jcu.edu.au
}

\author{
Ahmad Zahedi \\ College of Sciences, Technology, and Engineering \\ James Cook University, Queensland, Australia \\ Ahmad.Zahedi@jcu.edu.au
}

\begin{abstract}
This paper explores the current electric vehicle landscape in Australia and briefly examines the current research on smart charging. From this, a concept for a customer charging interface is proposed with additional features suggested to improve use-ability by a wide range of consumers. Next, strategies for accurately modelling the energy management of electric vehicles are advised to allow for the proper analysis of different charging schemes. A charging strategy with a dynamic pricing scheme to allow flexible charging options for the customer is then developed which has the potential to be implemented relatively easily. To conclude the paper, recommendations are made to fully realise the benefits of grid-integrated electric vehicles.
\end{abstract}

Keywords: Electric Vehicle; Energy Management, Smart Grid

\section{INTRODUCTION}

The re-emergence of electric vehicles is heralding a new age of transport and energy as concerns for climate change and limited fossil fuel supplies drive the development of more efficient modes of transport. Electric vehicles (EVs) were first built in 1891 following the popularisation of electricity and shared the market with internal combustion engine (ICE) cars. However, ICE vehicles were initially favoured over electric vehicles due to the availability of gasoline and the limited range of EVs [1] .

In more recent times, there has been an increasing need to shift to more low emission sources for both financial and environmental reasons. With rising oil prices and Australia's transport sector producing substantial carbon emissions, electric vehicles (EVs) are once again becoming a viable alternative to petrol driven cars. EVs don't require fuel and instead receive their power from power stations and renewable energy sources. When receiving power from the latter, they can be considered zero emission vehicles. They are ideal for metropolitan areas as they produce no airborne particles, produce less noise pollution, and have less service requirements than ICE vehicles [2].
The main concern with an increased uptake of EVs is an increase in load on the power grid [3]. Numerous studies have been conducted to evaluate the potential impact of $\mathrm{EV}$ charging on power distribution systems. Articles [4],[5],[6],[7], and [8] investigate the impact of EVs (both hybrid and fully electric) on power systems and find that the system is likely to suffer an increase in peak load as well as increased power losses if the vehicles are charged in an uncontrolled manner. Paper [9] explores the effect EVs will have on distribution congestion and reports that distribution congestion is likely to occur if $\mathrm{EV}$ uptake is greater than $11 \%$ (that is, $11 \%$ of residential cars are electric vehicles).

Further studies have investigated a variety of systems to efficiently charge EVs. The most commonly proposed method of mitigating the impact of EVs on the power grid is to use emerging smart grid technology to charge the vehicles. There are various definitions of what exactly constitutes a smart grid but the general consensus is that a smart grid is a self-healing electrical network that intelligently integrates households (and other users) connected to the grid thus encouraging customers to have an active participation in their energy needs. This results in a more efficient, sustainable form of energy supply [1].

Currently in Australia, smart grid technology is still in its early stages. Victoria first introduced smart meters into residential homes in September 2009, and several other power companies (Essential Energy, Ausgrid, and Endeavour Energy) have undertaken trials involving advanced metering technology in the last decade. Despite the numerous benefits this technology can offer customers, concerns for loss of privacy and control over electricity demand has discouraged consumer engagement in smart grid initiatives [10].

For the successful integration of electric vehicles into the smart grid to be possible, it is essential that customers are encouraged with clear information and financial incentives to responsibly manage the smart charging of their car. Customers will require information regarding their energy 
consumption and real time pricing information via in-home and in-car displays with programs that require them to make the fewest explicit decisions [10].

The purpose of this paper is to examine the existing research into the future potential of EVs and use this information to guide the development of a user interface for EV customers, a model for energy management of EVs connected to the smart electricity grid, and control strategy for grid-integrated EVs. This will be used to identify a range of recommendations for consideration that will help in fully realising the benefits of grid-integrated EVs.

\section{EXISTING RESEARCH AND PROPOSED STRATEGIES}

As previously mentioned, customer engagement is essential to realising the full benefits of grid integrated electric vehicles. Several studies have been conducted to gauge people's attitudes towards EVs (i.e. purchase motivations, preferred charging style) and understand what barriers need to be overcome to increase their uptake. Articles [11] and [12] showed that running costs, environmental impact, and ease of charging were important factors in considering the purchase of an EV. Article [13] also elaborated on the necessity of having a charging point at home as well as the option for fast charging and found that the top three incentives for purchasing an electric vehicle were tax exemptions for the car, free parking and toll discounts.

Some of the research into electric vehicles has been examining the link between a battery's state of charge (SOC) and the load profile of the grid. Theoretically, a battery charges at the same rate of energy demand regardless of SOC when charging with constant power. This is confirmed in articles [14] and [15] where it is shown that the grid will experience a constant level of load for the time the car is charging. The latter paper further explores the demand profile of an EV battery charging under different conditions. It showed, via both simulation and with real components, that a constant current charging scheme results in up to an $11.4 \%$ increase in load when charging approaches working voltage (ie $90 \%$ charge). This can be explained by the battery's increase in voltage as it approaches full charge (as the current is constant, an increase in voltage will result in an increase in power). These articles also confirmed that decreasing the efficiency of the charger resulted in an increased charging time and recommended that the SOC gets no lower than $20 \%$ for battery health.

The uncontrolled charging of EVs (often referred to as dumb charging or on demand charging) has been extensively examined and is often used as a baseline for comparing the impacts of different smart charging schemes on peak load. Unlike dumb charging, smart charging endeavours to minimise peak load and flatten the overall load profile through a variety of methods. [16] One of the more simple smart charging methods is load offsetting which encourages customers with financial incentives to charge after peak time. In Victoria, the demand management research project examined how easily such a strategy could be implemented. They found that delaying the charging of cars to off-peak periods was sufficient to manage the extra load on the system. Qualitative research was also undertaken to gauge customer's attitudes towards smart charging. The report showed that financial incentives would encourage off peak charging and that simple user interfaces allowed for better charge management [17].

In Queensland, Ergon energy has just completed a similar project and determined that managing peak demand by providing customers with more charging options was a valid strategy. The trial also highlighted the impact that driving habits would have on charging behaviour (customers who had to drive farther preferred on demand charging) [18]. The findings for both trials showed the potential of load offsetting to create an unwanted second peak which is not ideal.

The smart charging of electric vehicles is still an emerging area of study. As such, most of the current research into more complex methods is purely simulated. A variety of different smart charging methods have been theorised, one being coordinated charging [19-21]. The general aim of coordinated charging is to charge cars in a manner that flattens the load profile of the power grid over the course of the day. Article [19] uses an optimization algorithm formulated to minimize variations in the power load from the mean. This optimization model resulted in a flattened load profile due to EVs being scheduled by the program to charge in off peak times.

Articles [21], [22], and [23] examine the efficiency of the real-time coordination of EV charging with a time of use tariff initially sorting the vehicles into different priority zones. As mentioned previously, customers desire the ability to control how their cars are charged so a method like this could be easily implemented.

Another important component of smart charging that has been investigated is vehicle to grid (V2G) and vehicle to home (V2H) charging. That is, using an electric vehicle's battery as a distributed energy storage resource [24]. Article [24] examines the potential benefits of using EV batteries as a storage device for the smart grid which includes load shifting, outage protection, and peak shaving. The paper also examines how the integration of EVs into the smart grid could mitigate the negative impacts of fluctuating renewable sources (solar and wind power) and highlights possible challenges to successful V2G integration. Article [25] discusses the potential of $\mathrm{V} 2 \mathrm{G}$ capable vehicles to make grid management cheaper and power more reliable and stable through acting as storage for renewable energy sources and replacing time critical services such as spinning reserves. The potential of V2G and renewable energy integration is also explored in article [26] which supports the theory that V2G technology reduces system costs for energy providers. It also raises the issue of battery degradation due to constant charging and 
discharging and suggests that battery cycle life needs to be improved before V2G strategies can be financially beneficial to car owners.

\section{DEVELOPING A USER INTERFACE FOR CUSTOMERS}

Based on the information yielded from consumer surveys, running costs and convenience of charging are very important factors in the decision to own an electric vehicle. Thus an intuitive charging interface is necessary for controlling how the electric vehicle will be charged. The monitor's interface will have to be convenient and simple for the customer to use as well as give them full control over how their car is charged, especially in regards to charging cost. For this to be possible, the car owner will need to be supplied with the following information via the interface:

- State of Charge of the battery

- Condition of the grid (i.e. if it's at peak load, whether it has the ability to charge the car battery)

- Whether the grid/home can receive power from the battery

- Pricing (how the charging price will change depending on the impact of the grid $\rightarrow$ pricing curve should be similar to the shape of the expected load profile) [27]

- Car's electricity consumption by hour, day and week (tracking when the car is actually being charged)

- Average charging time/cost for car

- $\mathrm{V} 2 \mathrm{G} / \mathrm{V} 2 \mathrm{H}$ charging statistics

- Further information which may benefit customer includes:

- Comparison of the car's energy consumption to other cars

- Bill forecast for the car

- Budget target (to help manage costs)

- Advice on saving costs on charging and battery power

For the monitor to provide advice on saving battery power, it would need to have GPS functionality. This would enable the monitor to keep a log of the car owner's driving patterns and habits, and then suggest changes to their driving such as providing more efficient driving routes.

The interface would also allow the customer to input a range of information which would optimise the charging scheme for their car. This information would include desired charging time (i.e. what tariff they wish to charge on), whether they want to opt-in for V2H/V2G charging, expected departure time (to ensure their car is charged in time), and expected driving time/distance before charging again. This information, as well as the predicted load on the power grid would enable the car to be charged in the most optimum manner.

The in-car monitor would hopefully have a few language options as well as larger font options for people with visual impairments, with the interface being audible if needed to ensure that it is accessible to a wide variety of people. After the system has been in place for a while, prepaid charging schemes could possibly be implemented for users with a regular charging pattern which would result in a predictable load demand. There is also the opportunity for the development of a phone/tablet application which could act as an in-home interface for the charging station and car monitor, conveniently allowing the customer to check on their car from inside their house.

For V2G and V2H capability, it is essential that the car's power supply is bidirectional in nature. That is, the car's inbuilt inverter which is used convert the battery power to AC current to power the motor should also be able to supply power from the battery to the home or grid. It is also important that it matches the voltage and synchronizes the resulting signal to line phase [28]. The in-car monitor would be able to communicate with the inverter as the V2G/V2H capabilities are to be used at the customer's discretion to ensure sufficient battery reserves in the event the car needs to be driven for an emergency.

\section{MODELLING THE ENERGY MANAGEMENT OF ELECTRIC VEHICLES CONNECTED TO THE SMART GRID}

For the purposes of this paper, only the activity of residential cars and at home charging will be considered for energy management. Several factors need to be considered for modelling driver behaviour. These include driving distance, driving and plug-in time, time of day (as congestion usually occurs at specific times during the day), day of the week, and battery SOC. Micro simulation software such as MATSim [29] can be used to provide data representing individual cars plugging in to charge.

Spatial modelling can also be incorporated if it is predicted that certain suburbs would have a greater percentage of electric vehicles [5, 7]. This information is then combined with existing data for the charging profiles of EVs (charging time, load while charging) to yield an approximate model of vehicles connected to the grid.

The effects of different charging schemes can then be simulated using this model through software such as MATLAB [23]. For proper comparison, the system's load profile without EV charging and the system's load profile with dumb charging could both be used as baselines to determine the effectiveness of different charging strategies at flattening the load profile. The load profile data would come from existing information from power companies to ensure accurate results. It's expected that different regions would 
have different load profiles due to factors such as customer demographics, geography and weather.

\section{DEVELOPING A CONTROL STRATEGY FOR GRID-INTEGRATED EVS}

The main objective of the charging control strategy is to minimise costs for both the customer and power provider. Thus the scheme should encourage car owners to charge off peak where charging costs will be decreased. Customers will be given the option to select the time they wish their car to start charging, this decision will be based on the maximum rate they're willing to pay for charging their car (as mentioned previously they will be given an hourly pricing guide). They will also have the option to opt-in for vehicle to home/grid charging during peak (if the charging time they selected was not during peak hours).

The pricing scheme would likely be based on an existing tariff of the energy supplier. For this paper, Ergon's pricing tariffs will be used as a basis. During peak hours, the charging price would be close to the highest tariff and conversely during the time when the load on the grid is at its lowest the charging price would be closer to the lowest tariff. Depending on people's preference for particular charging times, it is expected for this pricing scheme to change on a monthly, weekly or even daily basis to discourage the creation of secondary peaks.

Once the car is plugged in to charge, the monitor will check if it is the desired charging time. If so, it will then check if the load on the power grid is less than a certain value (i.e. $95 \%$ of peak load) and commence charging if it is less than this value.
During peak time the car will provide power to the house to reduce some of the peak load if permitted by the car owner and not already charging. With vehicle to home charging, it is ideal that a certain percentage of charge remains in the battery in the event that the vehicle needs to be used in an emergency. As the recommended charge remaining in the vehicle is $20 \%$ for battery life [15], a minimum SOC of $30 \%$ should be sufficient for emergency trips. Since it is assumed that the house already has smart grid infrastructure in place, the in-car monitor and power supply would also be able to detect if there is an increase in load from the house (such as a washing machine turning on) and compensate for this load increase.

Otherwise, if the grid allows for charging of a customer's vehicle before their desired charging time, the car will charge at half load until fully charged or until the desired charging time is reached from which point it will continue to charge at full power.

Figure 1 below shows a breakdown of the charging plan. In the figure, " $\mathrm{X}$ " represents the maximum system load that will allow for charging (which would be $90-95 \%$ of the peak load), and "Y" represents the minimum SOC of the battery $(\sim 30 \%$ to allow for emergency trips).

Another charging option which could be explored more in the future is using refurbished EV batteries as an extra charging source for the car. These batteries could be charged from the house during the day via the grid or the house's own solar panels, if present. In the afternoon/night the car could then be charged mostly from the extra batteries without impacting on peak load.

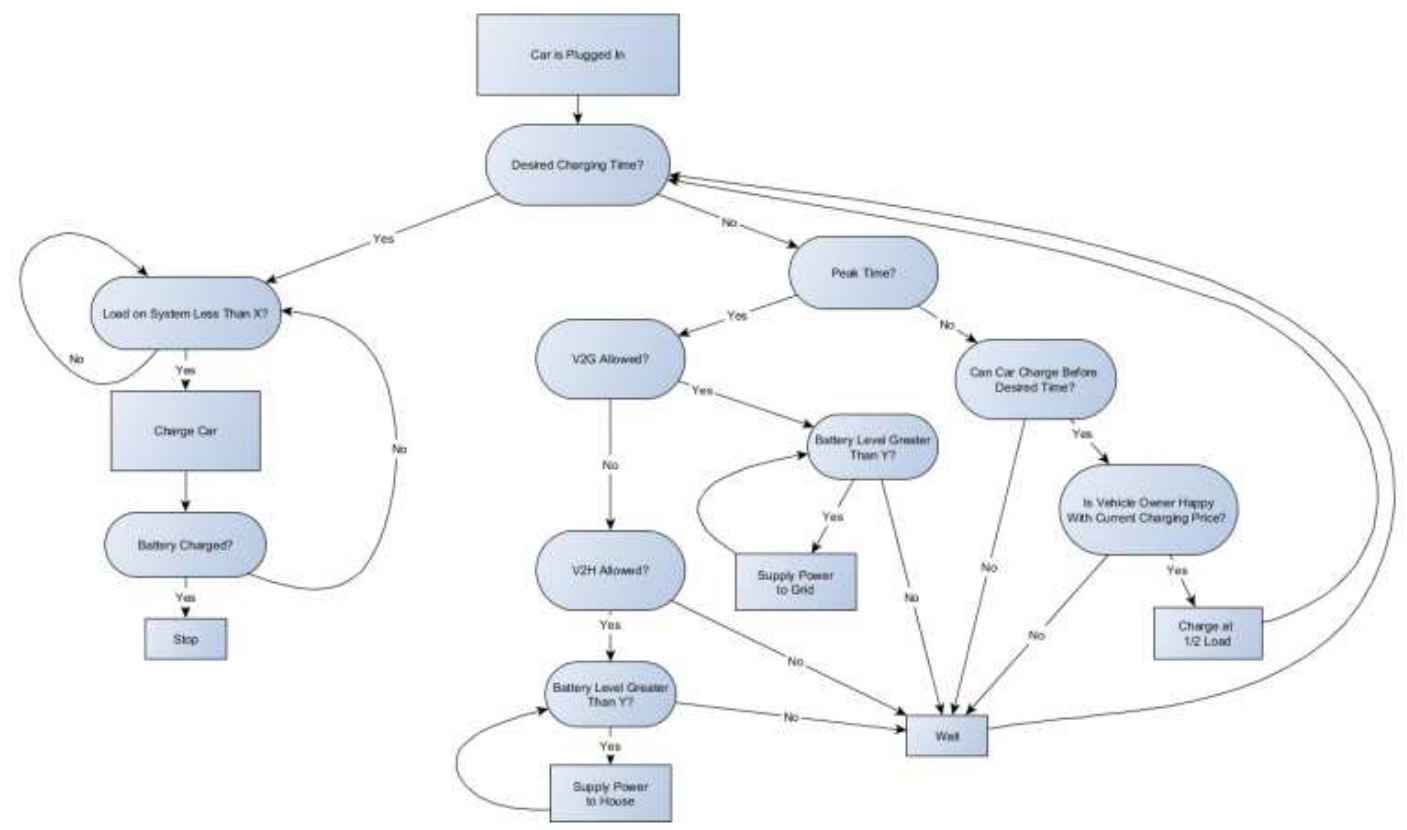

Figure 1 - Simplified Diagram of Charging Scheme for Individual Car 


\section{CONCLUSIONS AND RECOMMENDATIONS}

As one can see, there is still a lot of research to be done in the field of electric vehicle integration and, while simulated research have seen encouraging results, more real world testing needs to be done to confirm these outcomes. The possibilities for $\mathrm{V} 2 \mathrm{G}$ and $\mathrm{V} 2 \mathrm{H}$ technologies in particular are looking very promising.

In order to fully realise the benefits of the grid-integration of EVs, it is highly recommended that a flexible car charging scheme is implemented with the option for owners to provide power from their car to their house or back into the grid. This ensures benefits for both the power company and the customers, the customers are able to save money and have more control over their charging habits while the power company experiences less strain on the power grid.

Further research into improving the grid-integration of EVs involves investigating the practicality of EV batteries as storage for renewable energy sources, considering factors other than system load and customer preferences in scheduling the charging of vehicles, and exploring the benefits of other smart charging technologies. As this paper serves more as a guide for developing an efficient charging system for EVs, this would hopefully encourage the development of a prototype charging module to test ease of use for customers as consumer involvement is essential to the success of electric vehicle integration into the smart grid.

\section{REFERENCES}

[1] Zahedi, A. Role of Electric Vehicles Integrated into the Smart Grid Environment. in Hong Kong International Conference on Engineering and Applied Science. 2013. Hong Kong.

[2] Mader, T. and T. Braunl, Western Australian Electric Vehicle Trial. 2012, University of Western Australia: Australia. p. 1-59.

[3] Liu, R., L. Dow, and E. Liu. A survey of PEV impacts on electric utilities. in Innovative Smart Grid Technologies (ISGT), 2011 IEEE PES. 2011. IEEE.

[4] Shafiee, S., M. Fotuhi-Firuzabad, and M. Rastegar, Investigating the Impacts of Plug-in Hybrid Electric Vehicles on Power Distribution Systems. Smart Grid, IEEE Transactions on, 2013. 4(3): p. 1351-1360.

[5] Paevere, P., et al., Spatio-temporal modelling of electric vehicle charging demand and impacts on peak household electrical load. Sustainability Science, 2013: p. 1-16.

[6] Green II, R.C., L. Wang, and M. Alam, The impact of plug-in hybrid electric vehicles on distribution networks: A review and outlook. Renewable and Sustainable Energy Reviews, 2011. 15(1): p. 544-553.

[7] Paevere, P., et al., Spatial Modelling of Electric Vehicle Charging Demand and Impacts on Peak Household Electrical Load in Victoria, Australia, A.C.S.a.I.R.O. (CSIRO), Editor. 2012. p. 1-48.

[8] Schey, S., D. Scoffield, and J. Smart. A First Look at the Impact of Electric Vehicle Charging on the Electric Grid in The EV Project. in 26th Electric Vehicle Symposium (EVS-26), Los Angeles. 2012.

[9] SHAFIEE, S., M. FOTUHI-FIRUZABAD, and M. RASTEGAR, Investigating the Impacts of Plug-in Hybrid Electric Vehicles on
Distribution Congestion, in 22nd International Conference on Electricity Distribution. 2013: Stockholm.

[10] Smart Grid Australia - Maximising Consumer Benefit. p. 1-56.

[11] Gardner, J., G. Quezada, and P. Paevere, Social study on attitudes, drivers and barriers to the uptake of electric vehicles. An Electric Driveway Project Report, Commonwealth Scientific and Industrial Research Organisation (CSIRO), Australia, 2011.

[12] Ozaki, R. and K. Sevastyanova, Going hybrid: An analysis of consumer purchase motivations. Energy Policy, 2011. 39(5): p. 2217-2227.

[13] Plug-in electric vehicles - Changing perceptions, hedging bets: Accenture end-consumer survey on the electrification of private transport. 2011: Accenture.

[14] Park, W.-J., K.-B. Song, and J.-W. Park, Impact of Electric Vehicle Penetration-Based Charging Demand on Load Profile. Journal of Electrical Engineering \& Technology, 2013. 8(2): p. 244-251.

[15] Marra, F., et al. Demand profile study of battery electric vehicle under different charging options. in Power and Energy Society General Meeting, 2012 IEEE. 2012. IEEE.

[16] de Hoog, J., K. Handberg, and R. Jegatheesan, Demonstrating Demand Management: How Intelligent EV Charging Can Benefit Everyone, in EVS27. 2013: Barcelona, Spain.

[17] Demand management of electric vehicle charging using Victoria's Smart Grid. 2013. p. 1-49.

[18] Fowler, J. Trial finds mass uptake of electric vehicles could impact Ergon's network. 2013 27/06/13 [cited 2013 20th December]; Available from: https://www.ergon.com.au/about-us/news-room/mediareleases/regions/northern/trial-finds-mass-uptake-of-electric-vehiclescould-impact-ergons-network.

[19] Zhang, P., et al., A methodology for optimization of power systems demand due to electric vehicle charging load. Power Systems, IEEE Transactions on, 2012. 27(3): p. 1628-1636.

[20] Cao, Y., et al., An optimized EV charging model considering TOU price and SOC curve. Smart Grid, IEEE Transactions on, 2012. 3(1): p. 388393.

[21] Deilami, S., et al., Real-time coordination of plug-in electric vehicle charging in smart grids to minimize power losses and improve voltage profile. Smart Grid, IEEE Transactions on, 2011. 2(3): p. 456-467.

[22] Deilami, S., et al., Performance of Heuristic Optimization in Coordination of Plug-In Electric Vehicles Charging. International Journal of Renewable Energy and Biofuels, 2013. 2013: p. 1-15.

[23] Masoum, A.S., et al., A Heuristic Approach for Coordination of PlugIn Electric Vehicles Charging in Smart Grid. Energy Science and Technology, 2013. 5(2): p. 16-24.

[24] Zahedi, A., Electric vehicle as distributed energy storage resource for future smart grid. 2012.

[25] Kempton, W. and J. Tomić, Vehicle-to-grid power implementation: From stabilizing the grid to supporting large-scale renewable energy. Journal of Power Sources, 2005. 144(1): p. 280-294.

[26] Loisel, R., G. Pasaoglu, and C. Thiel, Large-scale deployment of electric vehicles in Germany by 2030: An analysis of grid-to-vehicle and vehicle-to-grid concepts. Energy Policy, 2013(0).

[27] Grahn, P., Electric Vehicle Charging Impact on Load Profile. 2013, $\mathrm{KTH}$.

[28] Kempton, W., et al., A test of vehicle-to-grid (V2G) for energy storage and frequency regulation in the PJM system. Univ. of Delaware, Tech. Rep, 2008.

[29] Galus, M.D., et al., Predictive, distributed, hierarchical charging control of PHEVs in the distribution system of a large urban area incorporating a multi agent transportation simulation. 2011: ETH, Eidgenössische Technische Hochschule Zürich, IVT, Institut für Verkehrsplanung und Transportsysteme. 